\title{
DYSLIPIDAEMIA IN CKD PATIENTS AND ITS CORRELATION WITH SEVERITY OF RENAL DYSFUNCTION
}

\author{
Rina Mohanty', Ritesh Acharya², Pravat Kumar Thatoi ${ }^{3}$, Hrudananda Bhuyan $^{4}$, Satarupa Mohapatra 5 , Satyabrata Sahoo ${ }^{6}$
}

1Associate Professor, Department of Medicine, SCB Medical College, Cuttack, Odisha.

${ }^{2}$ Postgraduate Student, Department of Medicine, SCB Medical College, Cuttack, Odisha.

${ }^{3}$ Associate Professor, Department of Medicine, PRM Medical College, Baripada, Odisha.

${ }^{4}$ Postgraduate Student, Department of Medicine, SCB Medical College, Cuttack, Odisha.

${ }^{5}$ Postgraduate Student, Department of Medicine, SCB Medical College, Cuttack, Odisha.

${ }^{6}$ Postgraduate Student, Department of Medicine, SCB Medical College, Cuttack, Odisha.

\section{BACKGROUND}

ABSTRACT

Chronic kidney disease (CKD) is a significant global health problem with significant morbidity and mortality. Dyslipidaemia along with an abnormal apolipoprotein profile and composition is a common complication associated with the decline in eGFR in CKD. The association between abnormal lipid profile and severity of CKD has rarely been studied in a general population, especially in Indian setup and may have a future prognostic and management implication in patients with CKD.

Aims and Objectives- To study the pattern of lipid abnormalities in CKD patients and to correlate with severity of renal dysfunction.

\section{MATERIALS AND METHODS}

A descriptive comparative study was done using 50 cases of CKD of > 15 years age, along with 30 age and sex matched controls excluding confounding factors like diabetes, HTN, thyroid abnormalities, heart diseases, infection, inflammatory diseases, smoking, alcoholism etc. History, general and systemic examination, routine blood parameters, ECG, USG abdomen pelvis, serum total cholesterol, LDL, HDL, VLDL and triglycerides were done. The eGFR was calculated according to the CKD-EPI equation. Statistical analysis was done using student's t-test, ANOVA, Bonferroni test, Mann-Whitney U test, Chi-square test and Pearson's correlation. P value $<0.05$ was considered as statistically significant.

\section{RESULTS}

The lipid profile in cases were TC: $184.96 \pm 24.85 \mathrm{mg} / \mathrm{dL}$; TGL: $148.10 \pm 32.71 \mathrm{mg} / \mathrm{dL}$; HDL: $32.38 \pm 5.78 \mathrm{mg} / \mathrm{dL}$ LDL: $122.82 \pm$ $24.76 \mathrm{mg} / \mathrm{dL}$; VLDL: $29.68 \pm 6.54 \mathrm{mg} / \mathrm{dL}$. Correlation between eGFR shows a significant negative correlation with TC ( $\mathrm{p}=0.007)$, TGL $(p=0.002)$, LDL $(p=0.000)$ and VLDL $(p=0.002)$ and positive correlation with HDL $(p=0.000)$. Comparison of lipid profile with grades of eGFR shows significant association with TGL $(\mathrm{f}=3.804, \mathrm{p}=0.004)$, HDL $(\mathrm{f}=18.099, \mathrm{p}=0.000), \mathrm{LDL}(\mathrm{f}=3.793$, $\mathrm{p}=0.004)$ and VLDL $(\mathrm{f}=3.631, \mathrm{p}=0.005)$, but not with TC $(\mathrm{f}=2.194, \mathrm{p}=0.064)$.

\section{CONCLUSION}

In CKD depending on severity there is a rise in TC, TGL, LDL, VLDL and a fall in HDL depending on severity.

\section{KEYWORDS}

Chronic Kidney Disease, Total Cholesterol, Triglyceride, Low Density Lipoprotein, High Density Lipoprotein, Very High Density Lipoprotein, Disease Severity.

HOW TO CITE THIS ARTICLE: Mohanty R, Acharya R, Thatoi PK, et al. Dyslipidaemia in CKD patients and its correlation with severity of renal dysfunction. J. Evolution Med. Dent. Sci. 2018;7(11):1323-1327, DOI: 10.14260/jemds/2018/301

\section{BACKGROUND}

CKD encompasses a spectrum of different pathophysiologic processes associated with abnormal kidney function and a progressive decline in GFR. ${ }^{1}$ CKD is a significant global health problem. About $6 \%$ adult population in US have CKD stage 1 and 2, and $4.5 \%$ have CKD stage 3 and $4 .{ }^{1}$ Its prevalence is high in India with a study showing 229 /million population suffering from ESRD. ${ }^{2}$ Most common causes of CKD include diabetic nephropathy, glomerulonephritis, HTN associated CKD, ADPKD and cystic and tubulointerstitial nephropathy. ${ }^{1}$

'Financial or Other Competing Interest': None.

Submission 28-01-2018, Peer Review 20-02-2018,

Acceptance 27-02-2018, Published 12-03-2018.

Corresponding Author:

Dr. Ritesh Acharya,

Flat-404, Harihar Enclave, Goutam Nagar,

Bhubaneswar-751014,

Odisha, India.

E-mail: acharyaritesh1987@gmail.com

DOI: $10.14260 /$ jemds $/ 2018 / 301$

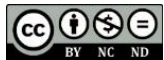

Various complications of CKD include fluid electrolyte and acid base abnormalities, cardiovascular, neuromuscular, gastrointestinal, nutritional, endocrine and dermatological complications. Dyslipidaemia is a common complication of CKD and lipoprotein metabolism alteration and is associated with the decline in GFR; hence, lipid profile depends on the level of kidney function and the degree of proteinuria.3,4 Disturbances in lipoprotein metabolism are evident even at the early stages of CKD and usually follow a downhill course that parallels the deterioration in renal function. ${ }^{5}$ Severe lipid metabolism disorders arise in patients with kidney failure and the lipid metabolism disorder peculiar to this patient group is known as uraemic dyslipidaemia, 5 which may accelerate its progression. ${ }^{6}$ Abnormal lipid profile in CKD includes hypertriglyceridaemia, increase in triglyceride remnant Lp (a), increase in VLDL, decrease in HDL, total cholesterol and LDL usually within normal limits except in nephrotic syndrome patients. ${ }^{7}$ The association between lipid profile and severity of CKD has rarely been studied in a general population, especially in our part of the country and 
may have a future prognostic and management implication in patients with CKD.

The present study evaluates the type of dyslipidaemia in CKD patients and correlates with severity of renal dysfunction in CKD patients.

\section{MATERIALS AND METHODS}

This study is a descriptive comparative study and conducted in Department of Medicine of SCB Medical College and Hospital, Cuttack, from December 2016 to November 2017. After clearance from Institutional Ethics Committee (IEC), we included 50 CKD patients admitted to medicine wards. Thirty age and sex matched controls were taken excluding confounding factors like diabetes, HTN, thyroid abnormalities, heart diseases, infection, inflammatory diseases, smoking, alcoholism etc. Written consent was obtained from each individual participating in the study.

Patient Selection Criteria: Males and females $>15$ years of age who were diagnosed as chronic kidney disease patients, attending PG Department of Medicine of SCB Medical College and Hospital were taken as cases.

Exclusion Criteria: Patients with history of alcoholism, chronic smokers, liver disease, hypothyroidism, metabolic syndrome, diabetes mellitus, hypertension, malignancy, coronary artery disease, history of lipid lowering drug intake and connective tissue disorders were excluded.

\section{Investigations}

All patients had undergone thorough clinical examination and laboratory investigations like complete blood counts, serum urea and creatinine, serum sodium and potassium, serum calcium, liver function tests, serum protein and albumin, blood glucose, arterial blood gases, lipid profiles, thyroid function tests and urine analysis. Electrocardiography and ultrasonography of abdomen were done on every patient. All blood samples were collected after 12 hours of fasting.

The eGFR was calculated according to the CKD- EPI (Chronic Kidney Disease Epidemiology Collaboration) equation, 2009. EGFR was graded G1, G2, G3, G4 and G5 as per the KDIGO 2012 guidelines. ${ }^{1}$ Urine albumin was graded on basis of heat coagulation test as 0 , trace $(\mathrm{T})+,++,+++$ and ++++ .

\section{Statistical Analysis}

The statistical analysis was done using the Statistical Package for Social Sciences (SPSS) version 21.0. Univariate analysis was used in description of demographic characteristics of the study population. Continuous variables were presented as means and standard deviation for unskewed data and median and interquartile range for skewed data. Student t-test was used to compare mean values (for two groups) and F test for Analysis of Variance (ANOVA) for more than two groups with unskewed data. Post hoc analysis was done using the Bonferroni test. Mann-Whitney U test was used to compare skewed data. Discrete variables were presented as frequency and percentages. Chi-square test was used to determine the significant associations between categorical variables. Pearson's correlation was used to determine association between eGFR and other variables. $\mathrm{P}$ value $<0.05$ was considered statistically significant and $<0.001$ was considered as statistically highly significant.
RESULTS

\begin{tabular}{|c|c|c|c|}
\hline \multirow{2}{*}{ Age (In Years) } & \multicolumn{2}{|c|}{ Study Group } & \multirow{3}{*}{$\begin{array}{c}\text { Chi-Square } \\
\text { Tests }\end{array}$} \\
\hline & Case & Control & \\
\hline $15-30$ & $2(4 \%)$ & $3(10 \%)$ & \\
\hline $31-45$ & $17(34 \%)$ & $10(33.3 \%)$ & \multirow{4}{*}{$\begin{array}{c}\text { Chi-square: } \\
2.048 \\
\text { df: } 3 \\
\text { p: } 0.562\end{array}$} \\
\hline $46-60$ & $24(48 \%)$ & $11(36.7 \%)$ & \\
\hline$>60$ & $7(14 \%)$ & $6(20 \%)$ & \\
\hline Total & $50(100 \%)$ & $30(100 \%)$ & \\
\hline Table 1. Ag & tribution & f Cases and & ntrols \\
\hline
\end{tabular}

\begin{tabular}{|c|c|c|c|}
\hline \multirow{2}{*}{ Sex } & \multicolumn{2}{|c|}{ Study Group } & \multirow{2}{*}{ Chi-Square Tests } \\
\cline { 2 - 3 } & \multicolumn{2}{|c|}{ Case Control } & \\
\hline Male & $29(58 \%)$ & $18(60 \%)$ & Chi-Square: 0.031 \\
\hline Female & $21(42 \%)$ & $12(40 \%)$ & df: 1 \\
\hline Total & $\mathbf{5 0}(100 \%)$ & $\mathbf{3 0}(\mathbf{1 0 0} \%)$ & p: 0.860 \\
\hline \multicolumn{2}{|c|}{ Table 2. Sex Distribution of Cases and Controls } \\
\hline
\end{tabular}

The age and sex distribution of cases and controls shows both the study groups are age and sex matched.

\begin{tabular}{|c|c|}
\hline eGFR (mL/ min./1.73 $\mathbf{~ m}^{\mathbf{}}$ ) & Cases (50) \\
\hline$\geq 90(\mathrm{G} 1)$ & $0(0 \%)$ \\
\hline $60-89(\mathrm{G} 2)$ & $0(0 \%)$ \\
\hline $45-59(\mathrm{G} 3 \mathrm{a})$ & $1(2 \%)$ \\
\hline $30-44(\mathrm{G} 3 \mathrm{~b})$ & $1(2 \%)$ \\
\hline $15-29(\mathrm{G} 4)$ & $17(34 \%)$ \\
\hline$<15(\mathrm{G} 5)$ & $31(62 \%)$ \\
\hline \multicolumn{2}{|c|}{ Table 3. Severity Grading of CKD Cases on Basis of eGFR } \\
\hline
\end{tabular}

Grading the cases in terms of severity showed $62 \%$ of the cases were in grade ' $\mathrm{g} 5$ ' and $34 \%$ were in grade ' $\mathrm{g} 4$.'

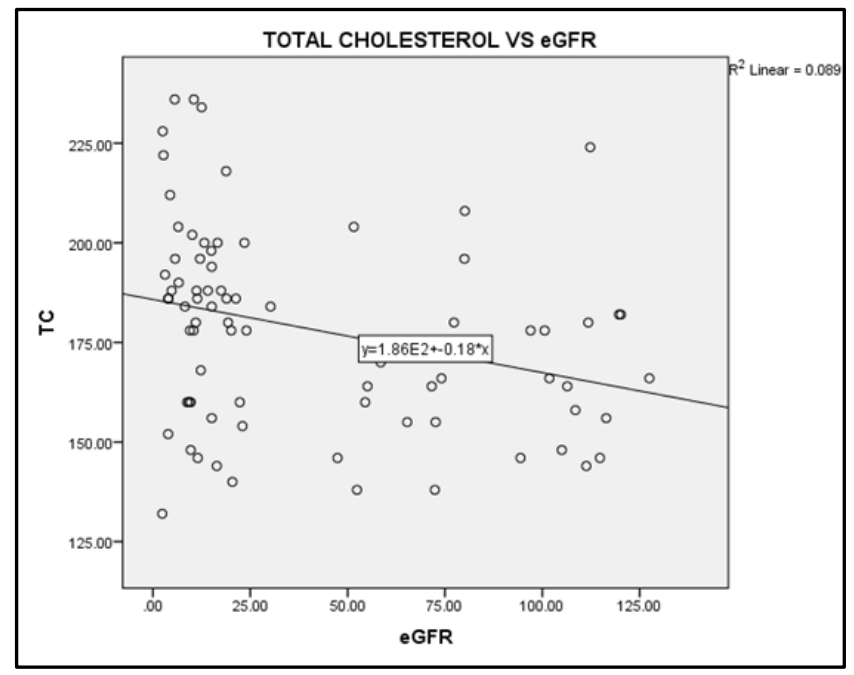

\begin{tabular}{|c|c|c|c|}
\hline \multirow[b]{2}{*}{ Mean \pm S.D. } & \multicolumn{2}{|c|}{ Study Group } & \multirow[b]{2}{*}{ Significance } \\
\hline & $\begin{array}{c}\text { Case } \\
(\mathrm{mg} / \mathrm{dL})\end{array}$ & $\begin{array}{l}\text { Control } \\
(\mathrm{mg} / \mathrm{dL})\end{array}$ & \\
\hline $\mathrm{TC}$ & $184.96 \pm 24.85$ & $166.90 \pm 19.81$ & 01 \\
\hline TGL & $148.10 \pm 32.71$ & $124.33 \pm 21.98$ & \\
\hline HDL & $32.38 \pm 5.78$ & $42.50 \pm 4.25$ & 00 \\
\hline LDL & $122.82 \pm 24.76$ & 100.33 & 00 \\
\hline VLDL & $29.68 \pm 6.54$ & $25.06 \pm 4.44$ & $\mathrm{p}=0.001$ \\
\hline \multicolumn{4}{|c|}{$\begin{array}{l}\text { Table 4. Comparison of Lipid Profile between Cases and } \\
\text { Controls (Independent Samples T-Test) }\end{array}$} \\
\hline
\end{tabular}

The comparison between lipid profiles of cases and controls showed significant difference between total cholesterol $(p=0.001)$, triglyceride $(p=0.001)$, high density 
lipoprotein $(\mathrm{p}=0.000)$, low density lipoprotein $(\mathrm{p}=0.000)$ and very low density lipoprotein $(\mathrm{p}=0.001)$.

\begin{tabular}{|c|c|c|}
\hline eGFR vs & Pearson's Correlation (r) & Significance (p) \\
\hline TC & -0.299 & 0.007 \\
\hline TGL & -0.347 & 0.002 \\
\hline HDL & 0.696 & 0.000 \\
\hline LDL & -0.408 & 0.000 \\
\hline VLDL & -0.336 & 0.002 \\
\hline \multicolumn{2}{|c|}{ Table 5. Correlation between eGFR and Lipid Profile } \\
\hline
\end{tabular}

Correlation between eGFR and lipid profile shows a significant negative correlation of eGFR with total cholesterol $(p=0.007)$, triglycerides $(p=0.002)$, low density lipoproteins $(p=0.000)$ and very low density lipoproteins $(p=0.002)$ and positive correlation with high density lipoproteins $(\mathrm{p}=$ 0.000).

\begin{tabular}{|c|c|c|c|}
\hline Lipid Profile & eGFR Grades & Mean \pm S.D. & P value \\
\hline \multirow{3}{*}{$\mathrm{TC}$} & $30-59$ & $166.57 \pm 22.38$ & \multirow{3}{*}{0.043} \\
\hline & $15-29$ & $179.05 \pm 21.25$ & \\
\hline & $<15$ & $187.61 \pm 26.85$ & \\
\hline \multirow{3}{*}{ TGL } & $30-59$ & $120.85 \pm 31.68$ & \multirow{3}{*}{0.002} \\
\hline & $15-29$ & $134.84 \pm 34.73$ & \\
\hline & $<15$ & $155.90 \pm 29.17$ & \\
\hline \multirow{3}{*}{ HDL } & $30-59$ & $39.14 \pm 3.84$ & \multirow{3}{*}{0.000} \\
\hline & $15-29$ & $35.58 \pm 5.14$ & \\
\hline & $<15$ & $30.38 \pm 5.42$ & \\
\hline \multirow{3}{*}{ LDL } & $30-59$ & $103.28 \pm 19.44$ & \multirow{3}{*}{0.003} \\
\hline & $15-29$ & $116.17 \pm 20.58$ & \\
\hline & $<15$ & $126.00 \pm 27.11$ & \\
\hline \multirow{3}{*}{ VLDL } & $30-59$ & $24.14 \pm 6.30$ & \multirow{3}{*}{0.003} \\
\hline & $15-29$ & $27.05 \pm 6.95$ & \\
\hline & $<15$ & $31.22 \pm 5.86$ & \\
\hline & various Gr & $\begin{array}{l}\text { Lipid Profile } \\
\text { of eGFR }\end{array}$ & \\
\hline
\end{tabular}

There is a significant rise in total cholesterol $(p=0.043)$, triglycerides $(p=0.002)$, low density lipoproteins $(p=0.003)$ and very low density lipoproteins $(p=0.003)$ and fall in high density lipoproteins $(p=0.000)$ with decreasing eGFR grades.

\begin{tabular}{|c|c|c|c|}
\hline & $\begin{array}{c}\text { Cases } \\
\text { (Mean } \pm \text { S.D.) }\end{array}$ & $\begin{array}{c}\text { Controls } \\
\text { (Mean } \pm \text { S.D.) }\end{array}$ & $\begin{array}{c}\text { Significance } \\
\text { (p) }\end{array}$ \\
\hline $\mathrm{Hb}$ & $8.782 \pm 1.705$ & $11.046 \pm 1.617$ & 0.000 \\
\hline S. Na & $130.64 \pm 11.82$ & $140.36 \pm 6.49$ & 0.000 \\
\hline S. K$^{+}$ & $3.98 \pm 0.70$ & $3.96 \pm 0.50$ & 0.871 \\
\hline S. Protein & $6.53 \pm 0.55$ & $7.28 \pm 0.45$ & 0.000 \\
\hline S. Albumin & $3.49 \pm 0.46$ & $4.29 \pm 0.42$ & 0.000 \\
\hline FBS & $97.94 \pm 15.89$ & $91.70 \pm 12.32$ & 0.069 \\
\hline PPBS & $127.14 \pm 14.12$ & $125.10 \pm 11.43$ & 0.505 \\
\hline HbA1C & $5.56 \pm 0.67$ & $5.72 \pm 0.52$ & 0.255 \\
\hline BMI & $19.97 \pm 3.13$ & $20.46 \pm 3.48$ & 0.513 \\
\hline Total & $0.70 \pm 0.24$ & $0.63 \pm 0.22$ & 0.187 \\
Bilirubin & $0.24 \pm 0.11$ & $0.19 \pm 0.10$ & 0.084 \\
\hline $\begin{array}{c}\text { Direct } \\
\text { Bilirubin }\end{array}$ & $24.8 \pm 8.46$ & $23.9 \pm 8.84$ & 0.652 \\
\hline AST & $24.32 \pm 8.72$ & $23.67 \pm 8.83$ & 0.748 \\
\hline ALT & $74.12 \pm 20.83$ & $84 \pm 23.17$ & 0.053 \\
\hline ALP & $2.53 \pm 0.93$ & $2.55 \pm 0.94$ & 0.956 \\
\hline TSH & $4.87 \pm 1.08$ & $4.52 \pm 1.10$ & 0.172 \\
\hline FT3 & $17.19 \pm 2.78$ & $15.93 \pm 3.33$ & 0.073 \\
\hline FT4 & & &
\end{tabular}

\begin{tabular}{|c|c|c|c|}
\hline $\begin{array}{c}\text { Mann- } \\
\text { Whitney U }\end{array}$ & Median & IQR & $\begin{array}{c}\text { Significance } \\
(\mathrm{p})\end{array}$ \\
\hline Blood urea & 75 & $38.00-128.25$ & 0.000 \\
\hline $\begin{array}{c}\text { Serum } \\
\text { creatinine }\end{array}$ & 3.25 & $1.025-5.725$ & 0.000 \\
\hline
\end{tabular}

Table 7. Comparison of various Parameters between Cases and Controls (Independent Samples T-Test)

On comparing various parameters between cases and controls, there is a significant decrease in $\mathrm{Hb}(\mathrm{p}=0.000), \mathrm{S} . \mathrm{Na}$ $(p=0.000)$, S. Protein $(p=0.000)$, S. Albumin $(p=0.000)$ and a rise in B. Urea $(p=0.000)$ and S. Creatinine $(p=0.000)$.

\begin{tabular}{|c|c|c|}
\hline eGFR vs & $\begin{array}{c}\text { Pearson } \\
\text { Correlation (r) }\end{array}$ & $\begin{array}{c}\text { Significance } \\
\text { (p) }\end{array}$ \\
\hline Hb & 0.502 & 0.000 \\
\hline BMI & 0.137 & 0.227 \\
\hline S. Na ${ }^{+}$ & 0.414 & 0.000 \\
\hline S. $\mathrm{K}^{+}$ & 0.052 & 0.647 \\
\hline B. Urea & -0.683 & 0.000 \\
\hline S. Creatinine & -0.682 & 0.000 \\
\hline S. Protein & 0.526 & 0.000 \\
\hline S. Albumin & 0.619 & 0.000 \\
\hline FBS & -0.192 & 0.088 \\
\hline PPBS & -0.156 & 0.167 \\
\hline HbA1C & 0.057 & 0.617 \\
\hline Total Bilirubin & -0.082 & 0.470 \\
\hline Direct Bilirubin & -0.120 & 0.287 \\
\hline AST & -0.040 & 0.726 \\
\hline ALT & -0.041 & 0.716 \\
\hline ALP & 0.181 & 0.108 \\
\hline TSH & -0.015 & 0.893 \\
\hline FT3 & -0.105 & 0.356 \\
\hline FT4 & -0.173 & 0.125 \\
\hline Table 8. Correlation between various \\
\hline Parameters and eGFR \\
\hline \multicolumn{2}{|l}{} \\
\hline
\end{tabular}

On correlating eGFR with various parameters, statistical significance was observed with $\mathrm{Hb}(\mathrm{r}=0.502, \mathrm{p}=0.000), \mathrm{S}$. Na $(\mathrm{r}=0.414, \mathrm{p}=0.000)$, B. Urea $(\mathrm{r}=-0.683, \mathrm{p}=0.000), \mathrm{S}$. Creatinine $(r=-0.682, p=0.000)$, S. Protein $(r=0.526, p=$ $0.000)$ and $S$. Albumin $(r=0.619, p=0.000)$.

\section{DISCUSSION}

Fifty cases of CKD were taken in the study, eliminating those which fell under the exclusion criteria. Thirty age and sex category matched healthy individuals were taken as controls. The age of the study population ranged from 25 to 75 years. Mean age of cases was $49.06 \pm 12.52$ years and controls was $49.6 \pm 12.07$ years. This was similar to that of CKD Registry of India 2007,8 where the mean age of cases was $48.3 \pm 16.6$ years and in the studies by Patel and Sirajwala ${ }^{9}$ and by Adejumo, Okaka and Ojogwu. ${ }^{10}$ As depicted in Table 1, the age group with maximum percentage of study population was 46 60 years' group with $48 \%$ of cases and $36.7 \%$ of controls in the same. In CKD Registry of India $20078,71.2 \%$ of the cases belonged to age group 19 - 60 years. As depicted in Table 2, the sex distribution showed $58 \%$ of cases were males and $42 \%$ were females. Among controls, $60 \%$ were males and $40 \%$ were females. The majority of our patients belonged to male gender. In CKD Registry of India 20078, the percentages of male cases were 68.9 and female cases were 31.1. Similar results to current study were seen in studies by Abraham et al11 and Ganta et al. ${ }^{12}$ The mean eGFR calculated by the CKD- 
EPI equation ${ }^{1}$ was found to be $13.12 \pm 8.67$ in cases and 88.44 \pm 23.9 in controls. There was a significant fall in eGFR in CKD cases. The mean eGFR of study by Sumanth and Shobharani ${ }^{13}$ was $22.22 \pm 8.70$ and that by Adejumo et al ${ }^{14}$ was 30.19 showing results similar to our study. On basis of severity grades $62 \%$ of cases were in G5 grade and 34\% of cases were in G4 grade as shown in Table 3. Most CKD cases belonged to grade G5 followed by G4. In CKD Registry India 2007, 50.3\% cases were in G5 and 24\% were in G4. In study by Ganta et $\mathrm{al}^{12} 45.71 \%$ cases were in G5 and $37.14 \%$ were in G4. These findings were similar to that in our study. As shown in Table 4 , the study of various lipid parameters showed the Mean \pm S.D. of serum total cholesterol to be $184.96 \pm 24.85$ in cases and $166.90 \pm 19.81$ in controls, and the difference was statistically significant with a 'p' value of 0.001 . The Mean \pm S.D. of serum triglycerides, high density lipoprotein, low density lipoprotein and very low density lipoprotein for cases were $148.10 \pm 32.71,32.38 \pm 5.78,122.82 \pm 24.76$ and 29.68 \pm 6.54 and for controls were $124.33 \pm 21.98,42.50 \pm 4.25$, $100.33 \pm 16.71$ and $25.06 \pm 4.44$ respectively. The differences were statistically significant with ' $p$ ' values of $0.001,0.000$, 0.000 and 0.001 respectively for serum triglycerides, high density lipoprotein, low density lipoprotein and very low density lipoprotein. The correlation between eGFR and various lipid parameters depicted in Table 5 showed a statistically significant correlation between eGFR and serum total cholesterol $(\mathrm{r}=-0.299, \mathrm{p}=0.007)$, serum triglycerides $(\mathrm{r}=$ $-0.347, p=0.002)$, serum high density lipoprotein $(r=0.696$, $\mathrm{p}=0.000)$, low density lipoprotein $(\mathrm{r}=-0.408, \mathrm{p}=0.000)$ and serum very low density lipoprotein $(r=-0.336, p=0.002)$. As shown in Table 6 on comparing the various lipid parameters with grades of eGFR, serum triglycerides $(\mathrm{F}=3.804, \mathrm{p}=$ 0.004), high density lipoproteins $(F=18.099, p=0.000)$, low density lipoproteins $(\mathrm{F}=3.793, \mathrm{p}=0.004)$ and very low density lipoproteins $(\mathrm{F}=3.631, \mathrm{p}=0.005)$ showed statistical significance, but no such significance was observed for serum total cholesterol $(\mathrm{F}=2.194, \mathrm{p}=0.064)$. These findings indicate a rise in serum total cholesterol, triglycerides, low density lipoproteins, very low density lipoproteins and a fall in high density lipoproteins in CKD with fall in eGFR. Similar changes in lipid profile were seen by Machnur and Chandrashekar, 15 Patel and Sirajwala, ${ }^{9}$ Ganta V et al,12 Attman, Samuelsson and Alaupovic,16 Mannangi et al and Wang et al,17 Paul and Kurien 18 in separate studies showed significant inverse correlation between triglyceride and GFR and significant positive correlation between high density lipoprotein and GFR ( $\mathrm{p}=<0.001)$.

Table 7 depicted that comparing Mean \pm S.D. of haemoglobin levels of case and controls showed a value of $8.782 \pm 1.705$ in cases and $11.046 \pm 1.617$ in controls with a ' $p$ ' value of 0.000 . This shows a fall in haemoglobin with CKD. Similar reports have been given by studies of Chonchol et $\mathrm{al}^{19}$ and Ortega et al. ${ }^{20}$ For BMI, it was $19.97 \pm 3.13$ for cases and $20.46 \pm 3.48$ for controls. The values were not statistically significant with a ' $p$ ' value of 0.513 . The CKD Registry of India $2007^{8}$ had majority of patients between BMI range of 18.5 and 24.9. For serum sodium, the Mean \pm S.D. of cases was $130.64 \pm 11.82$ and controls was $140.36 \pm 6.49$. The values were statistically significant with a ' $p$ ' value of 0.000 . This indicates the presence of significant hyponatraemia in CKD patients. For potassium, it was found to be $3.98 \pm 0.70$ and $3.96 \pm 0.50$ for cases and controls respectively with no statistical significance $(\mathrm{p}=0.871)$. The median of blood urea and serum creatinine were $75(\mathrm{IQR}=38-128.25)$ and 3.25 $(\mathrm{IQR}=1.025-5.725)$ respectively. The values were statistically significant with 'p' values of 0.000 for both. This indicates a significant rise in blood urea and serum creatinine in CKD patients. Similar results have been reported by Lakshmi, Subhashini and Swami. ${ }^{21}$ The Mean \pm S.D. of serum protein and serum albumin were $6.53 \pm 0.55$ and $3.49 \pm 0.46$ for cases, and $7.28 \pm 0.45$ and $4.29 \pm 0.42$ for controls respectively. The values were statistically significant with ' $p$ ' values of 0.000 for both. This indicates a fall in serum protein and albumin in CKD. Similar report has been submitted by the study of Adejumo et al. ${ }^{10}$ As shown in Table 8, statistically significant correlation was found between eGFR and haemoglobin, serum sodium, serum protein, serum albumin, blood urea and serum creatinine with $r=0.502,0.414,0.526$, $0.619,-0.683$ and -0.682 respectively with ' $p$ ' value of 0.000 in all. Values of BMI and serum potassium did not show any statistical significance.

\section{CONCLUSION}

Our study revealed that there was significant dyslipidaemia in CKD patients. There was rise in total cholesterol, triglycerides, low density lipoproteins, very low density lipoproteins and a fall in high density lipoproteins in CKD. These changes in lipid profile varied significantly when correlated with fall in eGFR. There is significant change in all lipid parameters when compared with grades of eGFR.

\section{REFERENCES}

[1] Bargman JM, Skorecki K. Chronic kidney disease in Harrison's principles of internal medicine. Vol 2. 19th edn. McGraw-Hill Publication 2015;335:1811-21.

[2] Modi GK, Jha V. The Incidence of end-stage renal disease in India: a population-based study. Kidney Int 2006;70(12):2131-3.

[3] Cases A, Coll E. Dyslipidemia and the progression of renal disease in chronic renal failure patients. Kidney Int Suppl 2005;68(Suppl 99):S87-S93.

[4] Weiner DE, Sarnak MJ. Managing dyslipidemia in chronic kidney disease. J Gen Intern Med 2004;19(10):1045-52.

[5] Tsimihodimos V, Mitrogianni Z, Elisaf M. Dyslipidemia associated with chronic kidney disease. The Open Cardiovascular Medicine Journal 2011;5:41-8.

[6] Tudor MN, Mitrea A, Popa SG, et al. Apolipo proteins: Good markers for cardiovascular risk in patients with CKD and dyslipidemia. Romanian Journal of Diabetes, Nutrition and Metabolic Diseases 2014;21(3):185-91.

[7] Ulosoy S, Ozkan G. Lipid abnormalities in haemodialysis patients. Haemodialysis 2013;6:101-25.

[8] Dash ASC, Rana DS, Sharma RK, et al. 2nd Annual Report CKD Registry of India, Indian Society of Nephrology 2007.

[9] Patel L, Sirajwala H. Serum Apolipoprotein A-1, Apolipoprotein B and Apo B/Apo A-1 ratio as cardiovascular risk indicators in patients of chronic renal failure. International Journal of Biomedical and Advance Research 2014;5(5):234-6. DOI:10.7439/ijbar 
[10] Adejumo OA, Okaka EI, Ojogwu LI. Lipid profile in predialysis chronic kidney disease patients in southern Nigeria. Ghana Med J 2016;50(1):44-9.

[11] Abraham G, Sundaram V, Sundaram V, et al. C-reactive protein, a valuable predictive marker in chronic kidney disease. Saudi J Kidney Dis Transpl 2009;20(5):811-5.

[12] Ganta V, Yalamanchi RP, Mahanta KC, et al. A study of lipid profile in non-diabetic chronic kidney disease. Int J Adv Med 2016;3(4):965-70.

[13] Sumanth BK, Shobharani B. Comparative study of Hscrp in chronic kidney disease. IOSR Journal of Pharmacy 2015;5(7):8-12.

[14] Adejumo OA, Okaka EI, Okwuonu CG, et al. Serum Creactive protein levels in pre-dialysis chronic kidney disease patients in southern Nigeria. Ghana Med Journal 2016;50(1):31-8.

[15] Machnur B, Chandrashekar. Lipid abnormality in chronic kidney disease: descriptive study. Int Journal of Med Research 2016;1(3):19-21.
[16] Attman PO, Samuelsson O, Alaupovic P. Lipoprotein metabolism and renal failure. Am J Kidney Dis 1993;21(6):573-92.

[17] Chu M, Wang AY, Chan IH, et al. Serum small-dense LDL abnormalities in chronic renal disease patients. British Journal of Biomedical Science 2012;69(3):99-102.

[18] Paul JK, Kurien SV. Study of lipid profile in chronic kidney disease patients of non-diabetic etiology and its relation to serum calcium. JMSCR 2017;5(9):2828490.

[19] Chonchol M, Lippi G, Montagnana M, et al. Association of inflammation with anaemia in patients with chronic kidney disease not requiring chronic dialysis. Nephrol Dial Transplant 2008;23(9):2879-83.

[20] Ortega O, Rodriguez I, Gallar P, et al. Significance of high C-reactive protein levels in pre-dialysis patients. Nephrol Dial Transplant 2002;17(6):1105-9.

[21] Lakshmi MSR, Subhashini YR, Swami KSR. Study of lipid profile in chronic renal failure. J Evid Based Med Healthc 2016;3(32):1508-15. 